\title{
Coumarin-induced skin necrosis
}

LLOYD W. BROOKS, JR, DO

FRANCIS X. BLAIS, DO

\section{Coumarin skin necrosis is a} rare and usually unpredictable complication of coumarin therapy, occasionally leading to death. Onset is usually between the third and sixth day of coumarin therapy. The patient most commonly complains of pain in a region of abundant subcutaneous fat, with progression to erythema, petechiae, and gangrenous necrosis. Thrombosis of the dermal and the subcutaneous veins is demonstrated pathologically. We describe a case and review the pathogenesis, treatment, and prevention of this lesion.

(Key words: Coumarin therapy, skin necrosis, anticoagulation therapy)

Coumarin skin necrosis is a rare and usually unpredictable complication of coumarin congener anticoagulant therapy (Table 1). Occasionally, this complication leads to death. The more common complications of coumarin therapy, such as subcutaneous hemorrhage, intramuscular hematoma, visceral intramural bleeding, and cutaneous reactions are directly related to anticoagulation, while coumarin-induced skin necrosis has well-defined histopathologic changes consistent with thrombosis and infarction (Table 2).

\section{Report of a case}

An 81-year-old woman with chronic dementia was admitted to the hospital from a nursing home, with deep venous thrombosis of the left thigh that was confirmed by venogram. Constant infusion of heparin was instituted, and anticoagulation was maintained at two times the control partial thromboplas-

At the time this article was written, Dr Brooks was a cardiology fellow, Riverside Hospital, Trenton, Mich; and Dr Blais is an associate professor, Medicine Department, Texas College of Osteopathic Medicine, Fort Worth. Dr Brooks is currently in private practice of cardiology, Fort Worth.

Reprint requests to Lloyd W. Brooks, Jr, DO, PO Box 470097, Fort Worth, TX 76147-0097. tin time. The patient's initial course was uncomplicated. On the seventh hospital day, heparin therapy was discontinued; $10 \mathrm{mg}$ of sodium warfarin was given orally, followed thereafter with $2.5 \mathrm{mg}$ daily, maintaining the prothrombin time at 27.8 seconds (control, 12.5 seconds). On the ninth day of hospitalization, the patient was discharged on a daily regimen of warfarin ( $2.5 \mathrm{mg}$ orally).

Two days after discharge, the patient was readmitted when nursing home personnel noticed a bright erythematous spot on the lateral aspect of the patient's right hip early in the morning, which enlarged, turned purple, and began to spread down the leg. A second area of erythema was noticed on the patient's left shoulder. The patient denied having suffered any trauma. Prothrombin time on admission was 22.8 seconds (control, 11.2 seconds; normal, < 14 seconds), partial thrompoplastin time was 30 seconds (normal, $<40$ seconds), and thrombocytopenia was now present (platelet count, 50 $\times 10^{9} / \mathrm{L}$; normal, 150 to $400 \times 10^{9} / \mathrm{L}$ ). Findings were consistent with coumarin-induced skin necrosis.

Warfarin therapy was stopped and heparin therapy was initiated after a bone marrow aspirate was obtained from the posterior iliac crest, and a biopsy specimen was obtained from the margin of the lesion on the thigh. Results of a bone marrow and peripheral smear were normal, and the thrombocytopenia was considered consumptive. Histologic study of the lesional biopsy specimen showed a scattering of mononuclear inflammatory cells and extravasation of erythrocytes in the papillary dermis. A large number of vessels within the subcutis showed evidence of thrombosis, with focal areas of hemorrhagic fat necrosis.

The patient continued to deteriorate and died of cardiac arrest on the ninth hospital day. No postmortem examination was obtained.

\section{Discussion}

Coumarin-congener-associated skin necrosis was first reported by Flood and coworkers ${ }^{3}$ in 1943 as thrombophlebitis migrans disseminata with breast involvement. Verhagen ${ }^{4}$ more accurately described the entity in 1954 . In a series of 13 patients with diagnoses including 


\begin{tabular}{|lc|}
\hline \multicolumn{1}{|c|}{$\begin{array}{c}\text { Table 1 } \\
\text { Coumarin Congeners Implicated in Production of Hemorrhagic } \\
\text { Skin Lesions as a Complication of Anticoagulant Therapy }\end{array}$} \\
\hline \multicolumn{1}{|c|}{ Agent } & $\begin{array}{c}\text { No. of } \\
\text { reported } \\
\text { cases }\end{array}$ \\
\hline $\begin{array}{l}\text { Bishydroxycoumarin (Dicoumarol) } \\
\text { Phenprocoumon (Marcumar, foreign trade name; } \\
\text { Liquamar, United States) }\end{array}$ & 27 \\
$\begin{array}{l}\text { Phenindoione (Danilone, Hedulin) } \\
\text { Acenocoumarol (Sintrom) }\end{array}$ & 20 \\
$\begin{array}{l}\text { Ethyl biscoumacetate (Tromexan ethyl } \\
\text { acetate, Dicoumacyl [available outside } \\
\text { United States]) }\end{array}$ & 3 \\
$\begin{array}{l}\text { 3,3-Ethyl-bis-(4-oxycumarin) } \\
\text { (Pertromben and Thromboton [available } \\
\text { outside United States]) } \\
\text { Sodium warfarin (Coumadin sodium) }\end{array}$ & 7 \\
\hline
\end{tabular}

fractures, postpartum state, thyroidectomy, and thrombosis, he concluded that "any disease, when complicated by a thrombosis and treated with dicumarol . . . can lead to the discussed haemorrhagic complications." Kipen ${ }^{5}$ was the first to prop erly ascribe the gangrenous changes to anticoagulant therapy. Since Kipen's description in 1961, approximately 200 cases have been reported in the literature.

Skin necrosis occurs in approximately $0.1 \%$ of patients receiving anticoagulant therapy with a coumarin derivative. ${ }^{6}$ Most patients $(90 \%)$ are middle-aged, obese women ${ }^{1}$ who are being treated for thrombophlebitis of the lower extremities, pulmonary embolus, or cerebrovascular or coronary thrombosis. The onset and course of skin necrosis occur in a consistent pattern. ${ }^{7}$ Onset is between the third and sixth day of coumarin therapy, with the patient complaining of pain in a region of abundant subcutaneous fat. Sites of involvement are most commonly the buttocks, breasts, thighs, anterior aspect of the calves, and dorsum of the feet.

The patch is typically erythematous, with poor demarcation and often edema. Petechiae develop, followed within a few hours by ecchy- motic discoloration surrounded by an erythematous halo. Bullae may occur that contain sterile serosanguineous fluid, and are often followed by hemorrhagic infarcts and gangrenous necrosis that involve deeper tissues, producing sloughing that may require acute surgical debridement, skin grafting, or amputation. Usually, no extension of the lesion occurs. ${ }^{1,8,9}$

Numerous cases of full recovery without sequelae have been reported ${ }^{6}$ Clinical differentiation between subcutaneous hemorrhage and skin necrosis is paramount, because the treatment and prognosis are different. Nudelman and Kempson ${ }^{9}$ have summarized the differences (Table 3 ).

Histologically, the lesions demonstrate occlusion of dermal and subcutaneous veins, with fibrin thrombi and, occasionally, with neutrophilic vasculitis ${ }^{10}$; arteries appear to be spared while thrombosis is the inciting factor. Hypersensitivity vasculitis is unlikely because the lesion appears too late to be an immediatetype reaction and too soon to be an allergicmediated reaction. ${ }^{4}$ Skin tests for allergic vasculitis have been negative ${ }^{8}$ as have histologic studies. ${ }^{11}$ 
Table 2

Some Uncommon Adverse Reactions to Coumarin Drugs ${ }^{2}$

\section{Hemorrhagic reactions}

Central nervous system hemorrhage

Bleeding from eardrum

Hemarthrosis

Carpal tunnel syndrome

Intramuscular hematoma

Hemopericardium

Hemorrhagic pancreatitis

Hemorrhage from surreptitious self-administration

Adrenal hemorrhage

Hemorrhage into pituitary adenoma

Retroperitoneal and intramural intestinal bleeding
Other reactions

Urticaria

Extensive dermatitis

"Purple toes"

Drug interactions

Intestinal necrosis

Alopecia

Orange-red staining of hands and urine

Intestinal obstruction

Maculopapular, purpuric, or vesicular skin lesions

Table 3

Comparison of Hemorrhage and Necrosis in Patients

Receiving Coumarin Therapy ${ }^{1}$

\section{Hemorrhage}

Affects men and women equally

Onset unrelated to initiation of therapy

Corrected with administration of vitamin $\mathrm{K}$

Continuance of coumarin worsens complication

Heparin worsens complication

Necrosis absent

Surgery not indicated

\section{Necrosis}

Female predominance

Onset 3 to 6 days after initiation of therapy

Progresses despite administration of vitamin K

Continuance of coumarin has no effect on degree of complication

Heparin may be beneficial

Necrosis present

Surgery often necessary
In their pathogenic explanation, based on serial biopsy specimens, Nalbandian and coworkers ${ }^{1}$ proposed two stages to the disorder. The first stage occurs at the junction of the capillary and precapillary arteriole in the dermovascular loop. The clinical changes can be correlated with this localization, such as the initial erythematous flush with capillary dilation in the loop, followed by petechial formation when the capillary walls rupture. Ecchymoses represent coalescence of hemorrhage from the petechiae secondary to the previously administered anticoagulant.

The second stage-hemorrhagic infarct or gangrenous necrosis-correlates with stasis and subsequent thrombosis in the venules immediately distal to the dermovascular loop, where thrombotic occlusion of the larger veins of the dermis and subcutaneous tissue causes extensive necrosis and sloughing of the subcutaneous adipose tissue.

The coumarin congeners alter the hepatic synthesis of coagulation factors II, VII, IX, and $\mathrm{X}$ by interference with vitamin $\mathrm{K}$ utilization in the carboxylation of the glutamic acid residues of the precursors of these coagulation factors, resulting in dysfunctional factors. Because coumarin derivatives alter only the production of the vitamin $\mathrm{K}$-dependent factors, not preformed factors or their catabolism, depletion of the preformed factors must occur before full anticoagulation occurs.

The concentration of functional factor VII (plasma half-life, 5 to 6 hours) first decreases, then factor IX (half-life, 20 to 24 hours), X (halflife, 40 hours), and II (half-life, 60 hours). Antithrombogenic effects occur only after functional concentrations of factors IX and X are 
sufficiently diminished, usually in 2 to 7 days. ${ }^{12}$

Recent biochemical studies have defined a correlation between protein $\mathrm{C}$ deficiency and coumarin-induced skin necrosis. Protein $\mathrm{C}$ is a vitamin $\mathrm{K}$-dependent protein that, along with protein S and factors II, VII, IX, and X, is a $\gamma$-carboxyglutamic acid protein. ${ }^{13}$ In contrast with the vitamin $\mathrm{K}$-dependent coagulation factors, protein $\mathrm{C}$, with the aid of protein $\mathrm{S}$, induces a fibrinolytic state, with a decrease in whole blood clot lysis time but without systemic plasminogen activation. ${ }^{14}$ Activated protein $\mathrm{C}$ (protein $\mathrm{C}_{\mathrm{a}}$ ) selectively inactivates active cofactors $\mathrm{V}_{\mathrm{a}}$ and $\mathrm{VIII}_{\mathrm{a}}$, while inhibiting platelet coagulant activity by inactivation of platelet factor $\mathrm{X}$ and $\mathrm{V}_{\mathrm{a}}{ }^{8}$

Absence or deficiency of proteins $\mathrm{C}$ and $\mathrm{S}$ is strongly associated with congenital thrombotic disease $\mathrm{e}^{15}$ and recurrent venous thromboembolism. ${ }^{16}$ The ability of protein $\mathrm{C}_{\mathrm{a}}$ to promote clot lysis by enzymatically binding to, or degrading, an inhibitor of tissue plasminogen activator (TPA) may herald a synergistic use of protein $\mathrm{C}_{\mathrm{a}}$ in TPA-induced thrombolysis. ${ }^{17}$

Functionally, when coumarin therapy is initiated, protein $\mathrm{C}$ levels drop rapidly, paralleling factor VII levels; however, factor X and prothrombin are not depleted for 3 to 9 days. Therefore, with decreased protein $\mathrm{C}$ levels, the risk of thrombosis or extension of existing clots may increase until factor $\mathrm{X}$ and prothrombin are sufficiently depleted to achieve anticoagulation. Concurrent administration of heparin and warfarin during initial anticoagulation may prevent this clotting process. At the onset of coumarin therapy, however, large doses of coumarin should be avoided. Measurement of proteins $\mathrm{C}$ and $\mathrm{S}$ functional levels prior to initiation of coumarin therapy is ideal but impractical and not cost-efficient. ${ }^{3}$

Numerous regimens have been used to treat coumarin-induced skin necrosis, including local hypothermia, lumbar sympathectomy, vasodilators, vitamin $\mathrm{K}$, and vitamin $\mathrm{C}$, all without success. Nalbandian and associates ${ }^{18}$ report a successful regimen of heparin and vita$\min \mathrm{K}_{1}$, but only if initiated before the occurrence of infarcts. They also state that heparin will not prevent the occurrence of the necrosis.

Zauber and Stark ${ }^{19}$ report that they prevented skin necrosis in a patient who had previously had coumarin necrosis and who required reinitiation of coumarin anticoagulation by the infusion of fresh frozen plasma (which is rich in protein C) along with heparin for 3 to 5 days to maintain protein $\mathrm{C}$ levels until all vitamin $\mathrm{K}$-dependent factors were depleted. Continuation of coumarin therapy during the episode did not appear to hamper recovery or to cause further morbidity. Recurrence of skin necrosis on rechallenge, however, appears to be the exception rather than the rule.

\section{Summary}

Coumarin-congener necrosis may be precipitated by decreased levels of protein C, either inherently or iatrogenically, allowing formation or extension of clots by other remaining clotting factors. This clotting leads to infarction and necrosis of the dermis and subcutaneous adipose tissue.

Concomitant heparin therapy during initiation of low-dose coumarin therapy or therapy with coumarin congeners on day 1 of heparin administration may prevent the occurrence of the associated skin necrosis. The necrosis may also be prevented if the early signs (erythema, pain, and edema) are recognized and heparin therapy is initiated. Once infarction has occurred, surgical management may be the only available treatment.

1. Nalbandian RM, Litman RE, Farberow NL, et al: Petechiae, ecchymoses, and necrosis of skin induced by coumarin congeners. JAMA 1965;192:107-112.

2. Renick AM: Anticoagulant-induced necrosis of skin and subcutaneous tissue: Report of two cases and review of the English literature. South Med J 1976;69:775-778.

3. Flood EP, Redish MH, Bociek S, et al: Thrombophlebitis migrans disseminata: Report of a case in which gangrene of breast occurred (observations on therapeutic use of Dicumarol). NY State J Med 1943;43:1121-1124.

4. Verhagen $\mathrm{H}$ : Local hemorrhage and necrosis of skin and underlying tissues during anticoagulant therapy with Dicumarol or Dicumacyl. Acta Med Scand 1954;148:453.

5. Kipen CS: Gangrene of the breast: A complication of anticoagulant therapy. $N$ Engl J Med 1961;265:638-640.

6. Kahn S, Stern HD, Rhodes GA: Cutaneous and subcutane- 
ous necrosis as a complication of coumadin-congener therapy. Plast Reconstr Surg 1971;48:160.

7. Caldwell EH, Stewart S: Skin necrosis as a consequence of coumadin therapy. Plast Reconstr Surg 1983;72:231-232.

8. Esmon CT: Protein C: Biochemistry, physiology and clinical implications. Blood 1983;62:1155-1158.

9. Nudelman HL, Kempson RL: Necrosis of the breast: A rare complication of anticoagulant therapy. Am J Surg 1966;111:731.

10. Faraci PA, Dieterling RA, Stein AM, et al: Warfarin induced necrosis of skin. Surg Gynecol Obstet 1978;146:1121-1124.

11. Koch-Weser J: Coumarin necrosis. Ann Intern Med 1968;68:1365-1367.

12. Gilman AG, Rall TW, Nies AS, et al: Goodman and Gilman's The Pharmacological Basis of Therapeutics, ed 8. New York, Pergamon Press, Inc, 1990, pp 1319-1322.

13. Griffin JH, Mosher DF, Zimmerman TS, et al: Protein C, an antithrombotic protein, is reduced in hospitalized patients with intravascular coagulation. Blood 1982;60:261-264.

14. Van Hinsbergh VWM, Bertina RM, von Wijngaarden A, et al: Activated protein $\mathrm{C}$ decreases plasminogen activator-inhibitor activity in endothelial cell conditioned medium. Blood 1985;65:444-451.

15. Griffin JH, Evatt B, Zimmerman TS, et al: Deficiency of protein $\mathrm{C}$ in congenital thrombotic disease. $J$ Clin Invest 1981;68:1370-1373.

16. Comp PC, Esmon CT: Recurrent venous thromboembolism in patients with a partial deficiency of protein S. N Engl J Med 1985;311:1525-1528.

17. Sakata Y, Curriden S, Lawrence D, et al: Activated protein C stimulates the fibrinolytic activity of cultured endothelial cells and decreases antiactivator activity. Proc Natl Acad Sci USA 1985;82:1121-1125.

18. Nalbandian RM, Beller AK, Kamp AK, et al: Coumarin necrosis of skin treated successfully with heparin. Obstet Gynecol 1971;38:395-399.

19. Zauber NP, Stark MW: Successful warfarin anticoagulation despite protein $\mathrm{C}$ deficiency and a history of warfarin necrosis: Brief report. Ann Intern Med 1986;104:659-660. 